\title{
Effects of Selegiline in a retroviral rat model for neurodegenerative disease
}

\author{
Markus Czub*,1, Stephanie Czub², Georg Gosztonyi ${ }^{3}$, Eleni Koutsilieri ${ }^{4}$, Sieghart Sopper ${ }^{1}$, Justus G Müller², \\ Manfred Gerlach ${ }^{4}$, Peter Riederer ${ }^{4}$ and Volker ter Meulen ${ }^{1}$ \\ ${ }^{1}$ Institut für Virologie, Universität Würzburg, Versbacherstr.7, D-97078 Würzburg, Germany; ${ }^{2}$ Pathologisches Institut, \\ Universität Würzburg, D-97080 Würzburg, Germany; ${ }^{3}$ Abteilung für Neuropathologie, Universitätsklinikum Benjamin \\ Franklin, D-12200 Berlin, Germany; ${ }^{4}$ Klinische Neurochemie, Psychiatrische Klinik, Universität Würzburg, D-97080 \\ Würzburg, Germany
}

\begin{abstract}
Upon inoculation into neonatal rats, murine leukemia virus (MuLV) NT40 causes a non-inflammatory degeneration of the central nervous system. While microglia cells appear to be the major target cells within the brain parenchyma for neurovirulent MuLV, degenerating neurons do not express retroviral gene products. In order to protect rats from neuronal damage we treated retrovirally infected rats once with monoamine oxidase (MAO) B inhibitor Selegiline which - under different conditions - exerts neuroprotective effects. Unexpectedly, when administered at 17 days post-infection (d.p.i.) a single intraperitoneal dose of Selegilin (1 mg/kg bodyweight) significantly shortened the incubation period for neurological disease. In contrast, Selegiline given in a lower dosage $(0.05 \mathrm{mg} / \mathrm{kg}$ bodyweight) and/or at a different time point (13 d.p.i.) at the low $(0.05 \mathrm{mg} / \mathrm{kg}$ bodyweight) and the high dose $(1.0 \mathrm{mg} / \mathrm{kg}$ bodyweight $)$ had no effect on the outcome of neurological disease. Animals treated with Selegiline $(1.0 \mathrm{mg} / \mathrm{kg}$ bodyweight at 17 d.p.i.) contained higher amounts of viral loads in the CNS, higher numbers of brain cells expressing major histocompatibility complex class II molecules, and exhibited inhibition of MAO-B in comparison to untreated yet infected (control) animals. Supposedly, Selegiline activated the major target cell population of the CNS for MuLV-NT40, microglia, with the consequence of enhanced susceptibility for retroviral infection and triggered endogenous mechanism(s) involved in the pathogenesis of retroviral neurodegeneration.
\end{abstract}

Keywords: neurodegeneration; retrovirus; Selegiline; dopamine; microglia

\section{Introduction}

Infections with neurovirulent retroviruses can result in neurodegenerative disease. In rodents, some of the murine leukemia viruses $(\mathrm{MuLV})$ cause a noninflammatory neurodegeneration, restricted to selective areas of the central nervous system (CNS) and the spinal cord (Baszler and Zachary, 1990; Czub et al, 1994, 1995; Kay et al, 1991). Most neurovirulent MuLV as well as certain lentiviruses including the human, simian, and feline immunodeficiency viruses (HIV, SIV, FIV) exhibit a strong affinity for cells of the monocytic lineage, i.e. in the CNS these viruses infect primarily microglia cells (Brinkmann et al, 1992; Czub et al, 1995, 1996; Lynch et al, 1991). However, while infected

\footnotetext{
${ }^{*}$ Correspondence: M Czub

Received 15 March 1999; revised 17 May 1999; accepted 1 June 1999
}

microglia cells appear not to be morphologically altered, degenerating neurons do not express retroviral gene products (Baszler and Zachary, 1990; Czub et al, 1994, 1995; Kay et al, 1991; Koenig et al, 1986; Lynch et al, 1991; Wiley et al, 1986). It is thus likely that neurons are damaged by indirect mechanism(s) probably initiated from retrovirally infected microglia cells.

Attempts to prevent retroviral neurodegeneration after establishing viral infections of the CNS have generally failed. In a previous study, for example, we demonstrated that an otherwise highly efficient antiviral immune response to MuLV-FB29 was incapable of clearing a retroviral infection from the brain (Hein et al, 1995). As immunological mechanisms appear to be ineffective on retroviral CNS infection, the goal of the current study was to prevent retroviral induced neurodegeneration by pharmacological treatment. We chose Selegiline, a 
drug that is used alone or in combination with levodopa for symptomatic treatment of Parkinson's disease (Myllylä et al, 1996). Selegiline is an irreversible inhibitor of monoamine oxidase (MAO) B and - at higher concentrations - inhibits the reuptake of dopamine in dopaminergic neurons (Gerlach et al, 1996). Apart from its effects on MAO, Selegiline exerts some 'trophic-like' activities on brain cells. While the molecular mechanisms responsible for these activities of Selegiline are not clear, they appear to protect neurons from neurodegenerative insults, both in vivo (Sano et al, 1997; Semkova et al, 1996; ThyagaRajan et al, 1998) and in vitro (Heikkila et al, 1984; Langston et al, 1984; Salonen et al, 1996; Zhang and Yu, 1995). Here, we show that treatment of retrovirally infected rats with Selegiline accelerated retrovirally induced neurological disease, and enhanced retroviral gene expression within the CNS as well as microglial activation. We propose that otherwise beneficial effects of Selegiline might be deleterious if retroviral infection of the CNS precedes treatment with Selegiline.

\section{Results}

Early onset of neurological disease of retrovirally infected rats after a single dose of Selegiline

Intraperitoneal (ip) inoculation of neonatal rats with MuLV-NT40 caused neurological disease in almost all animals within 50 days. The incubation period was $38.3 \pm 1.4$ days (mean \pm standard error of the mean (s.e.m.) (Figure 1). First clinical signs were reflex abnormalities of the hind- and forelimbs, followed by ataxia and - in some advanced cases priapism (Czub et al, 1995).

In order to achieve prevention or retardation of neurological disease, we treated neonatally infected rats once with MAO-B inhibitor Selegiline $(1.0 \mathrm{mg} /$ $\mathrm{kg}$ bodyweight) at 13 d.p.i., i.e. before spongiform vacuolization occurred in the brain which began around 16 d.p.i. When given at 13 d.p.i., Selegiline did neither change the overall incidence, nor the quality, nor the length of the incubation period (37.6 \pm 1.8 days) for retroviral induced neurological disease as compared to untreated NT40 infected rats (Figure 1). Thus, neuroprotection appeared not to be achieved by Selegiline under these conditions.

However, when Selegiline $(1.0 \mathrm{mg} / \mathrm{kg}$ bodyweight) was administered ip into neonatally infected rats at 17 d.p.i., i.e. when pathological CNS alterations had already started to occur, the incubation period for neurological disease $(33.7 \pm 1.8$ days) was shortened by 5-7 days in comparison to untreated infected rats $(P<0.05$; Figure 1). In contrast, the length of the incubation period for neurological disease was not influenced by lower doses of Selegiline given either at 13 or at 17 d.p.i. $(0.05 \mathrm{mg} / \mathrm{kg}$ bodyweight, Figure 1; or $0.01 \mathrm{mg} / \mathrm{kg}$ bodyweight, data not shown).
Inhibition of MAO-B by Selegiline

One of the best characterized effects of Selegiline is the irreversible inhibition of MAO-B (Gerlach et al, 1996). As acceleration of neurological disease was only observed when Selegiline was given in a dosage of $1.0 \mathrm{mg} / \mathrm{kg}$ bodyweight at $17 \mathrm{~d} . \mathrm{p} . \mathrm{i}$. but not upon lower doses and/or administration at 13 d.p.i., we determined whether Selegiline induced acceleration of neurological disease correlated with inhibition of MAO-B. Lower doses of Selegiline did not inhibit MAO-B, neither when given at early or at later timepoints (at 17 d.p.i.) (Figure 2). Higher doses of Selegiline $(1.0 \mathrm{mg} / \mathrm{kg}$ bodyweight) inhibited MAO-B by at least $60 \%$, both, when given at 17 d.p.i. and at 13 d.p.i. (Figure 2 ). Thus, inhibition of MAO-B did not correlate with accelerated neurological disease.

\section{Enhanced expression of MHC II within the CNS}

Activation of glia cells is supposed to play a dual role in the pathogenesis of retroviral induced disease. On the one hand, activated glia cells may shed neurotoxic substances like cytokines and may thus contribute to neurodegeneration (Masliah et al, 1996). On the other hand, activation of glia cells has been demonstrated to result in enhanced suscept-

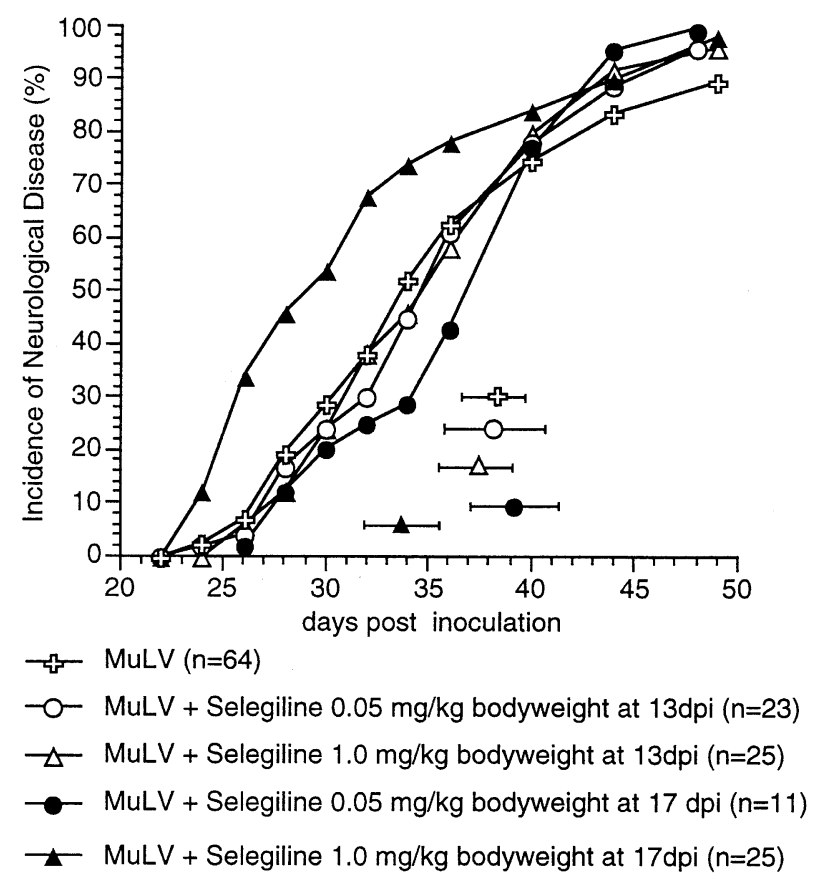

Figure 1 Influence of Selegiline on MuLV-NT40 induced neurological disease. Fischer rats were infected intraperitoneally with murine retrovirus NT40 at birth and treated with Selegiline (1.0 and $0.05 \mathrm{mg} / \mathrm{kg}$ bodyweight, respectively) at 13 and 17 days postinfection, respectively, or left untreated. For each scheme of treatment, $3-17$ independent experiments were set up. Animals were scored positive for neurological disease when they repeatedly exhibited reflex abnormalities and/or other neurological signs. Mean incubation periods are depicted as symbols between bars ( \pm s.e.m.). 
ibility for retroviral infection (Lynch et al, 1995). Selegiline has been shown to induce expression of several cellular genes some of which are associated with activation of glia cells (Biagini et al, 1993). Therefore, we determined numbers of activated cells within the brain, i.e. cells expressing MHC II. MHC II are only rarely found on glia cells from uninfected and/or untreated Fisher rats (Hein et al, 1995; Lassmann et al, 1991). In brain of NT40 infected yet untreated animals we found $81 \pm 36$ cells expressing MHC II (mean \pm s.e.m.; $n=15$ ), whereas brains from infected Selegiline treated rats $(1.0 \mathrm{mg} / \mathrm{kg}$ bodyweight at $17 \mathrm{~d}$.p.i.) contained $219 \pm 51$ (mean \pm s.e.m.; $n=13$ ) cells positive for MHC II immunolabeling (Table 1). These data show that retroviral infection in combination with Selegiline treatment triggered mechanism(s) resulting in enhanced activation of cells within the brain.

\section{Selegiline enhanced expression of retroviral gene} products in the CNS

Previous work revealed that the length of the incubation period for retroviral induced neurological disease correlated with viral loads in the CNS, i.e. high amounts of virus within the CNS corresponded with short incubation periods and vice versa (Czub et al, 1992). Employing an accurate technique, we determined the numbers of infected cells in the cerebellar cortex (CC) and in subcerebellar brainstem areas (SCBS) by means of immunohistochemistry at 25-36 d.p.i. During the course of viral infection, these regions contain high numbers of infected cells, both endothelial cells of the blood vessels and microglia cells. However, only the subcerebellar regions are subjected to intensive spongiform vacuolization (Czub et al, 1995). In brains of NT40 infected yet untreated animals we found $308 \pm 75$ cells expressing NT40 proteins (sum of CC: $112 \pm 35$ and SCBS: $196 \pm 72$; mean \pm s.e.m.; $n=11$ ), whereas brains of Selegiline treated rats $(1.0 \mathrm{mg} / \mathrm{kg}$ bodyweight at $17 \mathrm{~d}$.p.i.) contained $600 \pm 64$ (sum of CC: $216 \pm 25$ and SCBS: $384 \pm 48$; mean \pm s.e.m.; $n=12$ ) cells positive for staining with antiviral immune serum (Table 1). Similar results were obtained by in situ hybridizations (Figure 3). Thus, based on immunohistochemical data, treatment with MAO-B inhibitor Selegiline $(1.0 \mathrm{mg} / \mathrm{kg}$ bodyweight at $17 \mathrm{~d}$.p.i.) enhanced the numbers of retrovirally infected cells within the brain by approximately twofold.

Additionally, we isolated mRNA from total brains at 25-33 d.p.i. and quantified the relative amounts of viral RNA, both full length and spliced. The mean signal strength of all viral transcripts from individual brains of untreated rats was $117 \pm 26$ (mean \pm

Table 1 Number of brain cells expressing MHC II and viral proteins after treatment with Selegiline

\begin{tabular}{lcc}
\hline & Expression of MHC II $^{a}$ & Expression of virus $^{b}$ \\
\hline MuLV-NT40 & $81 \pm 36$ & $308 \pm 75$ \\
& $(n=15)$ & $(n=11)$ \\
MuLV-NT40+ $_{\text {Selegiline }}{ }^{\mathrm{c}}$ & $219 \pm 51$ & $600 \pm 64$ \\
Significance $^{\mathrm{d}}$ & $(n=13)$ & $(n=12)$ \\
Sin $^{2}$ & $P<0.03$ & $P<0.007$
\end{tabular}

${ }_{\mathrm{a}, \mathrm{b}}$ Numbers of brain cells expressing ${ }^{\mathrm{a}} \mathrm{MHC}$ II and ${ }^{\mathrm{b}}$ viral proteins, respectively, determined by immunohistochemistry (mean \pm s.e.m). ${ }^{\mathrm{c}} 1.0 \mathrm{mg} / \mathrm{kg}$ bodyweight at 17 d.p.i. ${ }^{\mathrm{d}}$ Student's $t$-test.

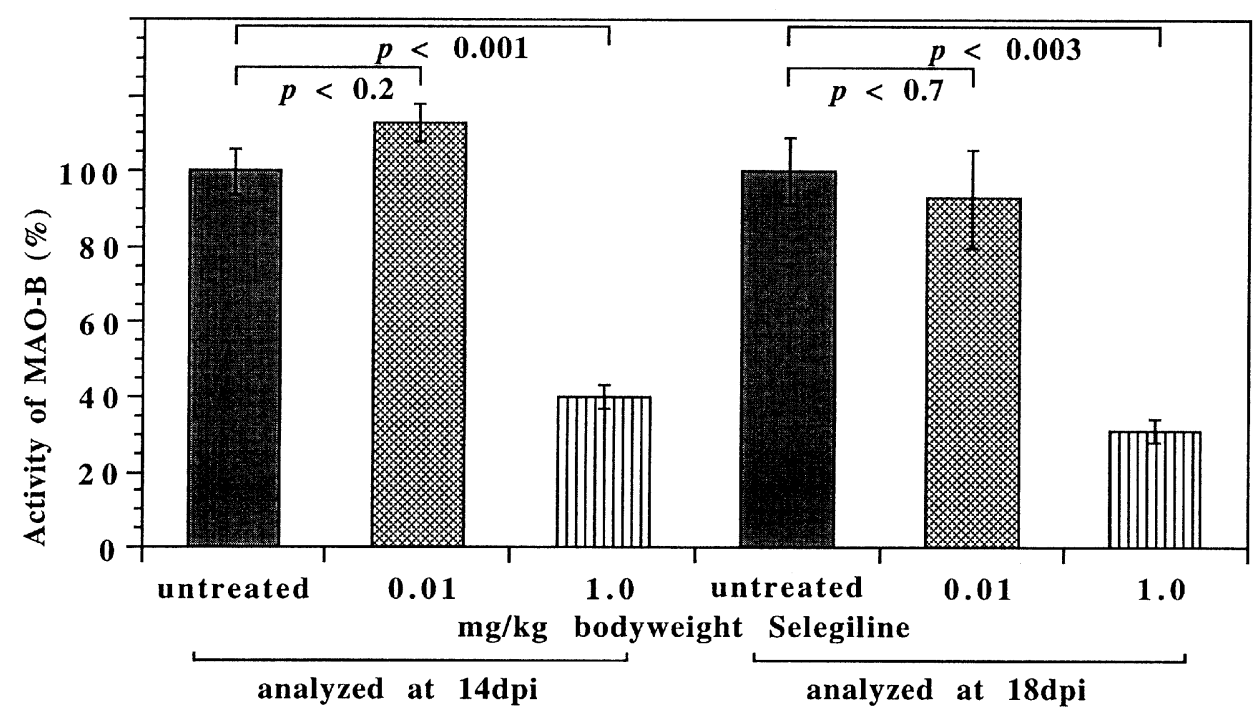

Figure 2 MAO-B activity measured ex vivo in striatum of MuLV-NT40 infected Fischer rats $24 \mathrm{~h}$ following treatment with Selegiline. Selegiline was injected ip at 13 or 17 d.p.i., at doses of 0.01 and $1.0 \mathrm{mg} / \mathrm{kg}$ bodyweight. Values are means of $3-8$ animals per group \pm s.e.m. $100 \%$ represents 0.198 (at 14 d.p.i.) and 0.425 (at 18 d.p.i.), respectively, $\mathrm{nmol} / \mathrm{mg} \times \min$. Values are regarded as significantly different from controls when $P<0.05$ (Student's $t$-test). 
s.e.m.; $n=9$ ). The mean signal strength of viral transcripts from the brains of NT40 infected rats that were treated with Selegiline $(1.0 \mathrm{mg} / \mathrm{kg}$ bodyweight at 17 d.p.i.) was $174 \pm 32$ (mean \pm s.e.m.; $n=9$ ). Thus, based on the amounts of mRNA of total brains, treatment with Selegiline $(1.0 \mathrm{mg} / \mathrm{kg}$ bodyweight at 17 d.p.i.) enhanced the amount of viral RNA, either through an increase of transcription of the proviral genome or by enhancing the number of infected cells within the CNS (Figure 4).

\section{Discussion}

The major finding of our study is that in a rodent model for non-inflammatory neurodegeneration Selegiline - under selective conditions - enhanced progression of neurological disease. Our results contrast numerous reports on beneficial effects of Selegiline, including those demonstrating treatment of Alzheimer's disease (Sano et al, 1997) and of Morbus Parkinson (Myllylä et al, 1996). It should be borne in mind, however, that the current study was performed with rats and not with primates including humans. It is also noteworth, that the dose of Selegiline used in our experiments was higher than the dose given to humans with Parkinson's disease.

A key factor in the pathogenesis of retroviral induced neurodegeneration including the AIDSdementia complex is the level of retroviral load in the CNS. Previous work shows that high amounts of retroviral gene products in the CNS correlate with short incubation periods and a high incidence for neurological disease (Czub et al, 1992; Robertson et al, 1997). The amount of viral load within the CNS and the cerebrospinal fluid appears to be similarly important for the development of neurological disease upon infection with the human immunodeficiency virus (HIV) (McArthur et al, 1997; Robertson et al, 1998). As animals treated with Selegiline
(1.0 $\mathrm{mg} / \mathrm{kg}$ bodyweight at $17 \mathrm{~d}$.p.i.) contained higher amounts of viral loads in the CNS than those without Selegiline treatment, acceleration of neurological disease upon treatment with Selegiline is attributed to the enhanced levels of viral load within the CNS.

Enhanced progression of neurological disease induced by Selegiline $(1.0 \mathrm{mg} / \mathrm{kg}$ bodyweight at 17 d.p.i.) not only correlated with high levels of

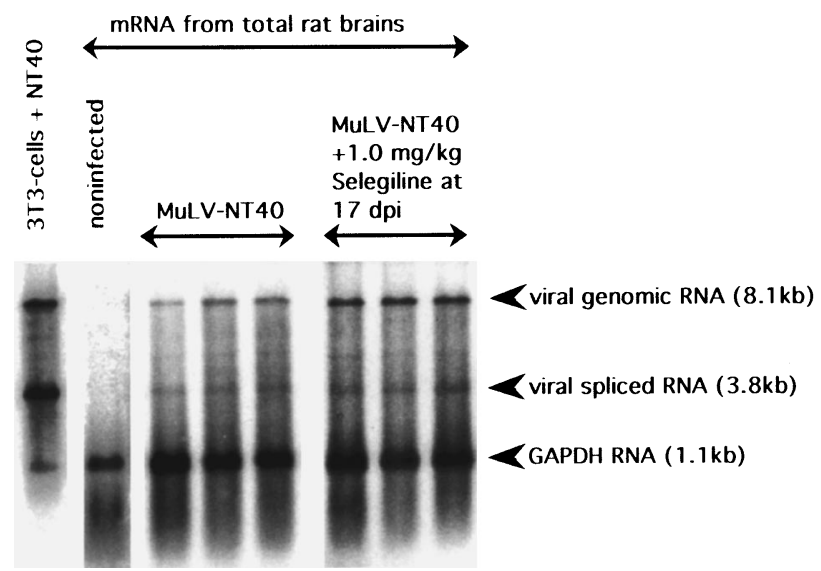

Figure 4 Northern blots using mRNA from total rat brains. Blots were probed with a probe encoding retroviral envelopesequences which resulted in signals representing viral full length genomic $(8,1 \mathrm{~kb})$ and spliced transcripts $(3,8 \mathrm{~kb})$. Simultaneously, a probe encoding housekeeping gene GAPDH was used, hybridizing with transcripts of 1,2 kb. Virus specific hybridization signals were adjusted to comparable levels by dividing the signal strengths of the viral signals by the respective signal strengths of the GAPDH signals. ${ }^{32} \mathrm{P}$-hybridization signals were analyzed and background corrected using a Phosphor imaging system from Molecular Dynamics. The mean signal strength of all viral transcripts from nine individual brains of untreated rats was $117 \pm 26$ (mean \pm s.e.m.), while the mean signal strength of viral transcripts from nine brains of NT40 infected rats that were treated with Selegiline $(1.0 \mathrm{mg} / \mathrm{kg}$ bodyweight at $17 \mathrm{~d}$.p.i.) was $174 \pm 32$ (mean \pm s.e.m.)
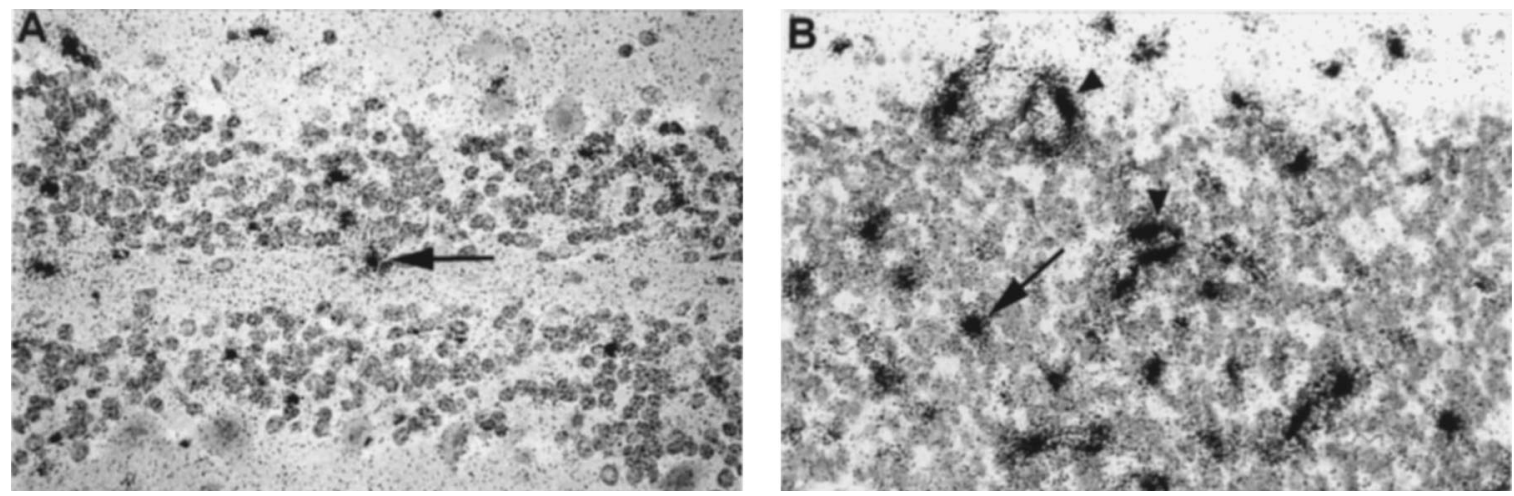

Figure 3 RNA-RNA in situ hybridization of MuLV infected rat brains. MuLV-RNA hybridization signals (arrows and arrowheads) are seen in some cells of the cerebellar cortex of rats neonatally infected with MuLV-NT40 (A). Treatment with Selegiline (1.0 mg/kg bodyweight at 17 d.p.i.) increased the frequency of virus-expressing cells (B). 
viral gene products within the CNS, but also with glial activation. By morphological criteria, these activated cells within the brain consisted mainly of microglia cells (S Czub, unpublished observation). Previously, it had been demonstrated that activation of microglia - due to focal CNS injury enhanced the susceptibility of these cells for retroviral infection (Lynch et al, 1995). Likewise, Selegiline is known of being capable to increase reactive gliosis (Biagini et al, 1993, 1994; Ju et al, 1994). It is thus possible that Selegiline by increasing reactive gliosis enhanced the susceptibility for retroviral infection within the CNS. Whether Selegiline has a direct effect on microglia or rather on other glia cells, like astrocytes, and by this an indirect influence on microglia cells remains to be determined. It must also be proven whether Selegiline might have a more direct effect on viral spread and/ or on viral transcription.

Additionally, it is possible that Selegiline triggered endogenous mechanism(s) that could directly be involved in the pathogenesis of retroviral neurodegeneration and subsequently led to enhanced neurological disease. Those mechanisms might include production of neurotransmitters, cytotoxins, interference with neural growth factors and/or loss of scavenger functions within the CNS (Masliah et al, 1996).

The effects of Selegiline observed in this study could be due to either (1) an increase of dopamine (Gerlach et al, 1996), (2) to the metabolites of Selegiline, especially amphetamine and metamphetamine (Gerlach et al, 1996), or (3) to an induction of gene expression (Tatton and Chalmers-Redman, 1996). Amphetamine and metamphetamine, and/ or inhibition of MAO-B and a subsequent increase of dopamine is unlikely to have played a role for enhancement of neurological disease, since neurological disease was not accelerated when MAO-B was inhibited by Selegiline given before the time spongiform neurodegeneration occurred. However, it is possible that at this early time a critical stage of postnatal CNS development prevented rats from becoming susceptible to enhanced retroviral neurodegeneration. This hypothesis is supported by findings on prenatal, i.e. in utero infection of mice with neurovirulent MuLV, after which brains of these mice had high levels of viral load already at birth, however, neurological disease did not start before 15 days postnatally and was thus not accelerated in comparison to postnatal infection (Lynch and Portis, 1993).

According to recent studies, transcriptional activation rather than inhibition of MAO-B is supposed to play a key role for neuroprotective effects of Selegiline (Semkova et al, 1996; Tatton and Chalmers-Redman, 1996; ThyagaRajan et al, 1998). In that same sense, Selegiline induced activation of glia cells - as demonstrated by enhanced expression of MHC II in our study - might have been beneficial for the CNS, under normal circumstances. However, due to their activated metabolism, brain cells were more susceptible to retroviral infection and expressed retroviral gene products to a higher degree. As a result, neurological disease was accelerated. Our findings may be relevant for other viral infections of the brain, like HIV, in which activation of the glia cells, e.g. by dopamimetic substances, could rather be harmful than helpful (Bell et al, 1996; Davies et al, 1997; Martinez et al, 1995).

\section{Material and methods}

Animal model

Neonatal Fisher (F344) rats were inoculated intraperitoneally (ip) with MuLV-NT40 $\left(10^{4}\right.$ focus forming units) which leads to persistent infection of several peripheral organs and the brain (Czub et al, 1995). There is no immune response towards the neonatal viral infection and no inflammation within degenerated brain tissue (Hein et al, 1995).

Selegiline was given ip at day 13 , i.e. before spongiform neurodegeneration occurred, or at day 17 post infection, i.e. after neurovacuolation had started. For single dose effects in adult rats, $0.25 \mathrm{mg}$ Selegiline per $\mathrm{kg}$ bodyweight has been reported to inhibit MAO-B completely (Knoll, 1993). For each scheme of treatment, 3-17 experiments were set up independently. Animals were killed by $\mathrm{CO}_{2}$ inhalation. All experiments were performed on the permission of the State of Bavaria, Germany, and in accordance with Federal and EU guidelines.

\section{Neurological testing}

Reflex functions were tested by lifting each animal by the tail and placing it on the edge of the cage (grabbing reflex) and by short falls (placing reflex). Later signs of neurological disease are ataxia and paralysis. Animals were scored positive for neurological disease when they repeatedly exhibited neurological signs. Selegiline injected into noninfected rats did not induce neurological signs (data not shown).

\section{Measurement of MAO-B activity (Tipton and Singer, 1993)}

Striata of rats were disrupted in $0.25 \mathrm{M}$ Saccharose in PBS ( $\mathrm{pH} 7.4,0.1 \mathrm{M})$ on ice using a glass homogenizer and a sonificator. Homogenates (225 $\mu$ l containing $400 \mu \mathrm{g}$ protein) were incubated in a shaking waterbath at $37^{\circ} \mathrm{C}$ for $5 \mathrm{~min}$. Twentyfive $\mu \mathrm{l}$ of $\beta$-[ethyl-1-14 $\mathrm{C}$ ]-phenylethylamine hydrochloride (PEA, $100 \mu \mathrm{M}$, specific activity $1.55 \mathrm{Gbq} /$ mmol; DuPont NEN) in 0.1 M PBS were added to $225 \mu \mathrm{l}$ homogenate and incubated at $37^{\circ} \mathrm{C}$ for $7 \mathrm{~min}$. After adding $250 \mu \mathrm{l}$ of $1 \mathrm{M} \mathrm{HCl}$, the acidified solution was extracted with $2 \mathrm{ml}$ of ethyl acetate by vigorous shaking for $15 \mathrm{~min}$. After centrifugation at $1000 \times \mathrm{g}$ for $5 \mathrm{~min}$, two phases were separated and $1 \mathrm{ml}$ of the organic phase containing the 
deaminated metabolites was counted with $4 \mathrm{ml}$ of biosolve cocktail (Rotiszint, Roth) in a liquid scintillation counter (Beckmann Instruments). MAO activity is given as nmol of products formed per mg protein per min. Recovery of labeled products was $98 \%$ of total radioactivity used. Values were corrected for blank activity and counting was quench corrected.

Immunohistochemistry and in situ hybridization Tissues were fixed in $3 \%$ formalin-PBS and embedded in paraffin. Immunohistochemistry and in situ hybridization was performed as described before (Hein et al, 1995). Brain cells positive for antiviral staining were counted in high power view (magnification $\times 200$ ) using an ocular grid (ten full fields per individual). Major histocompatibility complex class II molecules (MHC II) were recognized by monoclonal antibody OX6 (McMaster and Williams, 1979).

\section{Quantification of viral transcripts}

mRNA was isolated from total brains employing Oligo(dT $)_{25}$ Dynabeads following the recommendations of the manufacturer (Dynal). After Northern blotting, blots were probed with a viral envelope specific-probe (Hein et al, 1995) as well as with a probe for a housekeeping gene, rat glyceraldehyde3-phosphate dehydrogenase (GAPDH). Virus specific hybridization signals were adjusted to comparable levels by dividing the individual signal

\section{References}

Baszler TV, Zachary JF (1990). Murine retroviral-induced spongiform neuronal degeneration parallels resident microglial cell infection. Lab Invest 63: 612-623.

Bell JE, Donaldson YK, Lowrie S, McKenzie CA, Elton RA, Chiswick A, Brettle RP, Ironside JW, Simmonds P (1996). Influence of risk group and zidovudine therapy on the development of HIV encephalitis and cognitive impairment in AIDS patients. AIDS 10: $493-499$.

Biagini G, Frasoldati A, Fuxe K, Agnati LF (1994). The concept of astrocyte-kinetic drug in the treatment of neurodegenerative diseases: evidence for L-deprenylinduced activation of reactive astrocytes. Neurochem Int 25; $17-22$.

Biagini G, Zoli M, Fuxe K, Agnati LF (1993). L-deprenyl increases GFAP immunoreactivity selectively in activated astrocytes in rat brain. NeuroReport 4: 955-958.

Brinkmann R, Schwinn A, Narayan O, Zink C, Kreth H, Roggendorf W, Dörries R, Schwender S, Imrich H, ter Meulen V (1992). Human immunodeficiency virus in microglia: correlation between cells infected in the brain and cells cultured from infectious brain tissue. Ann Neurol 31: 361-365. strengths of the viral signals by the respective signal strengths of the GAPDH signals. ${ }^{32} \mathrm{P}$-hybridization signals were analyzed and background corrected using a Phosphor imaging system and Image Quant software from Molecular Dynamics.

\section{Statistical analyses}

Incubation periods, MAO-B inhibition, and numbers of brain cells expressing viral gene products and MHC II, respectively, are given as mean \pm standard error of the mean (s.e.m.). On these data, statistics were performed using Student's $t$-test. Kaplan-Meyer curves (Figure 1) were analyzed using rank ANOVA testing (Kruskal-Wallis-H test).

\section{Acknowledgments}

The authors would like to thank J Herold for helpful discussions, S Schimmer, U Sauer and E Bachmann for excellent technical assistance, and I Haubitz and Y Probst from the Rechenzentrum der Universität Würzburg for help with the statistical analyses. We also thank Asta Medica, Frankfurt, for providing Selegiline. This work was supported by grants from the Deutsche Forschungsgemeinschaft ( $\mathrm{Cz}$ 56/1-2), from the Bundesministerium für Bildung, Wissenschaft, Forschung und Technologie (II-068-88), the Wilhelm Sander-Stiftung, and the Max-Planck-Forschungspreis (V ter Meulen).

Czub M, Czub S, Rappold M, Mazgareanu S, Schwender S, Demuth M, Hein A, Dörries R (1995). Murine leukemia virus induced neurodegeneration of rats: enhancement of neuropathogenicity correlates with enhanced viral tropism for macrophages, microglia, and brain vascular cells. Virology 214: 239-244.

Czub M, McAttee FJ, Portis JL (1992). Murine retrovirusinduced spongiform encephalopathy: host and viral factors which determine the length of the incubation period. J Virol 66: 3298-3305.

Czub S, Lynch WP, Czub M, Portis JL (1994). Kinetic analysis of spongiform neurodegenerative disease induced by a highly virulent murine retrovirus. Lab Invest 70: $711-723$.

Czub S, Müller JG, Czub M, Müller-Hermelink H-K (1996). Nature and sequence of simian immunodeficiency virus-induced central nervous system lesions: a kinetic study. Acta Neuropathol 92: 487-498.

Davies J, Everall IP, Weich S, McLaughlin J, Scaravilli F, Lantos PL (1997). HIV-associated brain pathology in the United Kingdom: an epidemiological study. AIDS 11: $1145-1150$ 
Gerlach M, Youdim MBH, Riederer P (1996). Pharmacology of Selegiline. Neurology 47: S137-S145.

Heikkila RE, Manzino L, Cabbat FS, Duvoisin RC (1984). Protection against dopaminergic neurotoxicity of 1methyl-4-phenyl-1,2,5,6-tetrahydropyridine by monoamine oxidase inhibitors. Nature 311: 467-469.

Hein A, Czub S, Xiao LX, Schwender S, Dörries R, Czub $M$ (1995). Effects of adoptive immune transfers on murine leukemia virus-infection of rats. Virology 211: $408-417$

Ju WY, Holland DP, Tatton WP (1994). (-)-Deprenyl alters the time course of death of axotomized facial motoneurons and the hypertrophy of neighboring astrocytes in immature rats. Exp Neurol 126: 233246.

Kay DG, Gravel C, Robitaille Y, Jolicoeur P (1991). Retrovirus-induced spongiform myeloencephalopathy in mice: regional distribution of infected target cells and neuronal loss occurring in the absence of viral expression in neurons. Proc Natl Acad Sci USA 88: $1281-1285$.

Knoll J (1993). The pharmacological basis of the therapeutic effect of (-)-deprenyl in age-related neurological diseases in inhibition of monoamine oxidase B. In: Inhibitors of Monoamino Oxidase B: Pharmacology and Clinical Use in Neurodegenerative Disorders. Szelenyi I, (ed). Birkhäuser Verlag: Basel/ Switzerland, pp 145-168.

Koenig S, Gendelman HE, Orenstein JM, DalCanto MC, Pezeshkpour GH, Yungblut M, Janotta F, Aksamit A, Martin MA, Fauci AS (1986). Detection of AIDS virus in macrophages in brain tissues from AIDS patients with encephalopathy. Science 233: 1089-1093.

Langston JW, Irwin I, Langston EB, Forno LS (1984). Pargylin prevents 1-methyl-4-phenyl-1,2,5,6-tetrahydropyridine-induced Parkinsonism in primates. Science 225: 1480-1482.

Lassmann H, Zimprich F, Vass K, Hickey WF (1991). Microglial cells are a component of the perivascular glia limitans. J Neurosci Res 28: 236-243.

Lynch WP, Czub S, McAttee FJ, Hayes SF, Portis JL (1991). Murine retrovirus-induced spongiform encephalopathy: productive infection of microglia and cerebellar neurons in accelerated CNS disease. Neuron 7: $365-379$.

Lynch WP, Portis JL (1993). Murine retrovirus-induced spongiform encephalopathy: disease expression is dependent on postnatal development of the central nervous system. J Virol 67: 2601-2610.

Lynch WP, Robertson SJ, Portis JL (1995). Induction of focal spongiform neurodegeneration in developmentally resistant mice by implantation of murine retrovirus-infected microglia. J Virol 69: 1408-1419.

Martinez A, Sell M, Mitrovics T, Stoltenburg-Didinger G, Iglesias-Rozas J, Giraldo-Velasques M, Gosztonyi G, Cervos-Navarro J (1995). The neuropathology and epidemiology of AIDS. A Berlin experience. A review of 200 cases. Path Res Pract 191: 427-443.

Masliah E, Ge N, Mucke L (1996). Pathogenesis of HIV-1 associated neurodegeneration. Crit Rev Neurobiol 10: $57-67$.
McArthur JC, McClernon DR, Cronin MF, Nance-Sproson TE, Saah AJ, St Clair M, Lanier ER (1997). Relationship between human immunodeficiency virus-associated dementia and viral load in cerebrospinal fluid and brain. Ann Neurol 42: 689-698.

McMaster WR, Williams AF (1979). Identification of Ia glycoproteins in rat thymus and purification from rat spleen. Eur J Immunol 9: 426-433.

Myllylä VV, Sotaniemi K, Mäki-Ikola O, Rinne UK, Heinonen EH (1996). Role of Selegiline in combination therapy of Parkinson's disease. Neurology 47: S200-S209.

Robertson K, Fiscus S, Kapoor C, Robertson W, Schneider G, Shepard R, Howe L, Silva S, Hall C (1998). CSF, plasma viral load and HIV associated dementia. J Neurovirol 4: 90-94.

Robertson SJ, Hasenkrug KJ, Chesebro B, Portis J (1997). Neurologic disease induced by polytropic murine retroviruses: neurovirulence determined by efficiency of spread to microglial cells. J Virol 71: 5287-5294.

Salonen T, Haapalinna A, Heinonen E, Suhonen J, Hervonen A (1996). Monoamine oxidase B inhibitor Selegiline protects young and aged rat peripheral sympathetic neurons against 6-hydroxydopamine-induced neurotoxicity. Acta Neuropathol 91: 466-474.

Sano M, Ernesto C, Thomas RG, Klauber MR, Schafer K, Grundman M, Woodbury P, Growdon J, Cotman CW, Pfeiffer E, Schneider LS, Thal LJ (1997). A controlled trial of Selegiline, alpha-tocopherol, or both as treatment for Alzheimer's disease. $N$ Engl J Med 336: $1216-1222$

Semkova I, Wolz P, Schilling M, Krieglstein J (1996). Selegiline enhances NGF synthesis and protects central nervous system (CNS) neurons from excitotoxic and ischemic damage. Eur J Pharmacol 315: $19-30$.

Tatton WG, Chalmers-Redman RME (1996). Modulation of gene expression rather than monoamine oxidase inhibition: (-)-deprenyl-related compounds in controlling neurodegeneration. Neurology 47: S171-S183.

ThyagaRajan S, Felten SY, Felten DL (1998). Restoration of sympathetic noradrenergic nerve fibers in the spleen by low doses of L-deprenyl treatment in young sympathectomized and old Fischer 344 rats. $J$ Neuroimmunol 81: 144-157.

Tipton KF, Singer TP (1993). The biochemical assay for monoamine oxidase activity: problems and pitfalls. Biochem Pharmacol 46: 1311-1316.

Wiley CA, Schrier RD, Nelson JA, Lampert PW, Oldstone MBA (1986). Cellular localization of human immunodeficiency virus infection within the brains of Acquired Immune Deficiency Syndrome patients. Proc Natl Acad Sci USA 83: 7089-7093.

Zhang X, Yu PH (1995). Depletion of NOS activity in the rat dentate gyrus neurons by DSP-4 and protection by deprenyl. Brain Res Bull 38: 307-311. 